\title{
Pengamanan Data Clien Test Urine Pada BNN Kabupaten Deli Serdang Menggunakan Metode Merkle Hellman
}

\author{
Badrul Anwar, Azanuddin, Nurcahyo Budi Nugroho \\ *Sistem Informasi, STMIK Triguna Dharma
}

\begin{tabular}{l}
\hline Article Info \\
\hline Article history: \\
Received May $31^{\text {th }}, 2019$ \\
Revised June $12^{\text {th }}, 2019$ \\
Accepted Augs $07^{\text {th }}, 2019$
\end{tabular}

\section{Keyword:}

Kriptografi,

Merkle Hellman,

Pengamanan Data Client Test

Urine,

Keamanan Data

\begin{abstract}
Data client test urine sangat penting yang hanya boleh diketahui pihak tertentu saja. Pengiriman, penginputan dan penyimpanan data atau informasi tanpa dilakukan pengamanan akan bersiko terhadap manipulasi data. Dalam hal ini maka perlu dibutuhkan keamanan, salah satunya dengan melakukan keamanan data pada komputer untuk melidungi akses data dari pihak yang tidak berkepentingan tersebut maka sangat diperlukan enkripsi dan dekripsi. Algoritma yang digunakan disini adalah algoritma merkle hellman, dimana algoritma merekle merupakan cryptosystem asimetris kunci yang memiliki 2 (dua) kunci yaitu public key dan private key. Dengan menerapkan metode merkle hellman ini mampu memberikan pengamanan terhadap data clent test urine, sehingga data tersebut memiliki tingkat keamanan yang tinggi. Algoritma merkle hellman dalam mengamankan data client test urine dapat dilakukan menggunakan bahasa pemprograman visual basic 2008 .
\end{abstract}

Copyright () 2019 STMIK Triguna Dharma. All rights reserved.

\begin{tabular}{ll}
\hline First Author & \\
Nama & :Badrul Anwar \\
Kantor & :STMIK Triguna Dharma \\
Program Studi & :SistemInformasi \\
E-Mail & :Badrul@trigunadharma.ac.id
\end{tabular}

\section{PENDAHULUAN}

Badan Narkotika Nasioanal (BNN) Kabupaten Deli Serdang adalah sebuah Lembaga Pemerintah Non Kementrian (LPNK) Indonesia yang mempunyai tugas dibidang pencegahan, pemberantasan penyalahgunaan dan peredaran gelap narkotika di wilayah Kabupaten Deli Serdang. Badan Narkotika Nasional (BNN) Kabupaten Deli Serdang terdapat klinik yang difungsikan untuk client yang ingin melakukan test urine.

Dalam sebuah pelayanan test urine, data client test urine adalah data yang sangat penting dan dijaga kerahasiaannya. Data client test urine pada BNN Kabupaten Deli Serdang belum menerapkan sebuah sistem pengamanan data, sehingga data client test urine tersebut berpotensi untuk diubah dan dimanipulasi oleh pihak-pihak yang tidak bertanggung jawab untuk keperluan pribadi seperti pencemaran nama baik, penipuan, dan sebagainya. Untuk menjaga kerahasiaan dan keamanan data dari pihak-pihak yang ingin merubah dan memanipulasi data tersebut, maka diperlukan sebuah sistem keamanan data.

Karena data client test urine berupa data text, maka dari masalah yang telah diuraikan akan dibangun sebuah sistem keamanan untuk mengamankan data client test urine menggunakan metode Merkle Hellman pada kriptografi berbasis dekstop. Kriptografi adalah ilmu yang mempelajari tentang bagaimana cara penyandian/penyamaran data yang digunakan untuk keamanan informasi seperti kerahasiaan, keutuhan, dan otentikasi entitas data. Agar dapat dilakukan enkripsi dan deskripsi dengan baik dibutuhkan suatu algoritma untuk mengenkripsi dan deskripsi data, salah satunya metode Merkle Hellman. Metode Merkle Hellman merupakan cryptosystem asimetris kunci, yang berarti mengunakan kunci ganda yaitu, kunci publik dan kunci pribadi.

Dari pembahasan ini diharapkan sistem yang dibangun dapat membantu pihak BNN untuk melindungi data client test urine dari pihak-pihak yang tidak bertanggung jawab, maka dilakukan penelitian untuk pengamanan data client test urine dengan menerapkan kriptografi algoritma Merkle Hellman yang diberi judul "Pengamanan Data Client Test Urine Pada BNN Kabupaten Deli Serdang Menggunakan Metode Merkle Hellman". 


\section{METODE PENELITIAN}

\subsection{Keamanan Data}

Keamanan data sangatlah penting dalam proses pengiriman ataupun penerimaan data yang dilakukan melalui media komputer. Pengamanan data ini dilakukan dalam rangka menjaga kerahasiaan, keutuhan, keabsahan dan ketersediaan data. Sehingga untuk memenuhi hal tersebut diperlukan adaya upaya dalam pengamanan data yakni dengan enkripsi dan dekripsi. (Asriyanik, 2017)

\subsection{Kriptografi}

Kriptografi berasal dari Bahasa Yunani, menurut bahasa tersebut kata "kriptografi"dibagi menjadi dua, yaitu kripto dan graphia. Kripto berarti secret (rahasia) dan Graphia berarti writing (tulisan). Menurut terminologinya, kriptografi adalah ilmu dan seni untuk menjaga keamanan pesan ketika pesan dikirim dari suatu tempat ke tempat yang lain (Ariyus, $2006: 77$ ).

\subsection{Data Client Test Urine}

Data client merupakan informasi tentang seseorang yang berisi data pribadi seperti nama, alamat, tanggal lahir, nomor telepon, dan sejenisnya. Data ini berfungsi untuk mengetahui informasi dari seorang client.

Test urine adalah suatu metode pemerikasaan menggunakan urine (air seni) guna mendeteksi adanya gangguan dalam tubuh. Dalam pemeriksaan test urine yang dilakukan BNN bertujuan untuk mendeteksi adanya penggunaan obat-obatan terlarang pada seseorang. Jadi, data client test urine merupakan informasi dari seorang client yang melakukan test urine untuk keperluan tertentu.

\subsection{Metode Merkle Hellman}

Algoritma kriptografi Merkle Hellman atau pada umumnya dikenal dengan sebutan merupakan chiper yang ide awalnya dari algoritma kriptografi One Time Pad, yaitu kunci yang dibangkitkan secara random dan panjang kunci sepanjang plainteks yang akan dienkripsi. Tetapi pada algoritma kriptografi pembangkitan kunci-kunci tersebut secara otomatis dengan teknik berantai.(Siregar, 2013)

Rumus Proses Enkripsi:

$$
c=\sum_{i=1}^{n} \alpha_{i} \beta_{i} \ldots \ldots[1]
$$

\section{Keterangan:}

$c=$ Chiper Text

$\beta=$ Public Key

$\propto=$ Pesan / Plaintext

Rumus Private Key:

$$
q>\sum_{i=1}^{n} w_{i} \ldots \ldots[2]
$$

Rumus Public Key :

$$
\beta=w^{*} r \bmod q \ldots[\text { [3] }
$$

Proses Dekripsi:

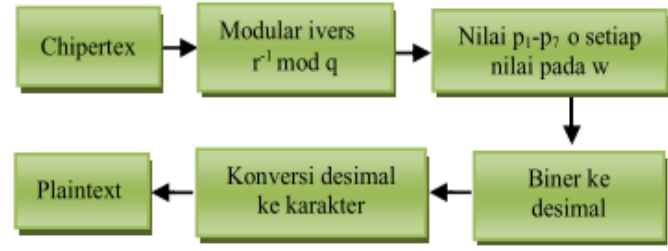

Rumus Modular Invers:

$$
\mathrm{M}=(\mathrm{r} * \mathrm{M} \bmod \mathrm{p}=1) \ldots \ldots[4]
$$

Rumus Chipper Data Mod q :

$$
K=C . r^{-1} \bmod q \ldots \ldots \ldots[6]
$$




\section{ANALISIS DAN HASIL}

\subsection{Algoritma Sistem}

Adapun algoritma dalam metode Merkle Hellman yang akan digunakan untuk menyelesaikan permasalahan adalah:

1. Menentukan kunci

2. Melakukan enkripsi

3. Melakukan dekripsi

\subsection{Proses Enkripsi}

3.2.1 Membuat Private Key (w,q,r)

Tabel 3.1 Private Key

\begin{tabular}{|c|c|}
\hline $\mathbf{w}$ & $\{2,7,11,21,42,89,180,354\}=\sum w=706$ \\
\hline $\mathbf{q}$ & 881 \\
\hline $\mathbf{r}$ & 588 \\
\hline
\end{tabular}

3.2.2 Membuat Public Key

Tabel 3.2 Public Key

\begin{tabular}{|c|c|c|}
\hline $\mathbf{w}$ & \multicolumn{2}{|c|}{$\boldsymbol{\beta}=\left(\mathbf{r} * \boldsymbol{w}_{\mathbf{i}}\right) \mathbf{m o d} \mathbf{q}$} \\
\hline 2 & $588 * 2 \bmod 881$ & 295 \\
\hline 7 & $588 * 7 \bmod 881$ & 592 \\
\hline 11 & $588 * 11 \bmod 881$ & 301 \\
\hline 21 & $588 * 21 \bmod 881$ & 14 \\
\hline 42 & $588 * 42 \bmod 881$ & 28 \\
\hline 89 & $588 * 89 \bmod 881$ & 353 \\
\hline 180 & $588 * 180 \bmod 881$ & 120 \\
\hline 354 & $588 * 354 \bmod 881$ & 236 \\
\hline
\end{tabular}

\subsubsection{Merubah Plaintext ke Biner 8 Digit}

Tabel 3.3 Data Biner

\begin{tabular}{|c|c|c|}
\hline Plainteks & ASCII & Binary (z) \\
\hline S & 83 & $\mathbf{0 1 0 1 0 0 1 1}$ \\
\hline $\mathbf{u}$ & 117 & $\mathbf{0 1 1 1 0 1 0 1}$ \\
\hline $\mathbf{s}$ & 115 & $\mathbf{0 1 1 1 0 0 1 1}$ \\
\hline $\mathbf{a}$ & $\mathbf{9 7}$ & $\mathbf{0 1 1 0 0 0 0 1}$ \\
\hline $\mathbf{n}$ & 110 & $\mathbf{0 1 1 0 1 1 1 0}$ \\
\hline $\mathbf{t}$ & 116 & $\mathbf{0 1 1 1 0 1 0 0}$ \\
\hline $\mathbf{i}$ & 105 & $\mathbf{0 1 1 0 1 0 0 1}$ \\
\hline
\end{tabular}

\subsubsection{Perhitungan Data Chiper}

Tabel 3.4 Perhitungan Data Chiper

\begin{tabular}{|c|l|c|}
\hline Binary $(\mathbf{z})$ & \multicolumn{1}{|c|}{$\sum \mathbf{c} * \boldsymbol{\beta}_{\mathbf{i}}$} & Chippertext \\
\hline \multirow{3}{*}{$\mathbf{0 1 0 1 0 0 1 1}$} & $(0 \times 295)+(1 \times 592)+(0 \times 301)+(1 \times 14)+(0 \times 28)$ & 962 \\
& + & \\
\hline \multirow{2}{*}{$\mathbf{0 1 1 1 0 1 0 1}$} & $(0 \times 353)+(1 \times 120)+(1 \times 236)$ & 1496 \\
& + & \\
\hline \multirow{2}{*01110011}{} & $(1 \times 353)+(0 \times 120)+(1 \times 236)$ & 1263 \\
& + & \\
\hline
\end{tabular}




\begin{tabular}{|c|l|c|}
\hline $\mathbf{0 1 1 0 0 0 0 1}$ & $\begin{array}{l}(0 \times 295)+(1 \times 592)+(1 \times 301)+(0 \times 14)+(0 \times 28) \\
+ \\
(0 \times 353)+(0 \times 120)+(1 \times 236)\end{array}$ & 1129 \\
\hline $\mathbf{0 1 1 0 1 1 1 0}$ & $\begin{array}{l}(0 \times 295)+(1 \times 592)+(1 \times 301)+(0 \times 14)+(1 \times 28) \\
+ \\
(1 \times 353)+(1 \times 120)+(0 \times 236)\end{array}$ & 1394 \\
\hline $\mathbf{0 1 1 1 0 1 0 0}$ & $\begin{array}{l}(0 \times 295)+(1 \times 592)+(1 \times 301)+(1 \times 14)+(0 \times 28) \\
+ \\
(1 \times 353)+(0 \times 120)+(0 \times 236)\end{array}$ \\
\hline $\mathbf{0 1 1 0 1 0 0 1}$ & $\begin{array}{l}(0 \times 295)+(1 \times 592)+(1 \times 301)+(0 \times 14)+(1 \times 28) \\
+ \\
(0 \times 353)+(0 \times 120)+(1 \times 236)\end{array}$ & 1157 \\
\hline
\end{tabular}

\subsection{Proses Dekripsi}

\subsubsection{Tabel Modular Invers}

Tabel 3.5 Modular Invers

\begin{tabular}{|c|c|c|}
\hline $\mathbf{M}$ & $(\mathbf{r} * \mathbf{M}) \mathbf{m o d} \mathbf{q}$ \\
\hline 1 & $588 * 1 \bmod 881$ & 588 \\
\hline 2 & $588 * 2 \bmod 881$ & 295 \\
\hline 3 & $588 * 3 \bmod 881$ & 2 \\
\hline$\ldots$. & $\ldots$. & $\ldots$. \\
\hline 442 & $588 * 442 \bmod 881$ & 1 \\
\hline
\end{tabular}

\subsubsection{Perhitungan Data Chiper Mod q}

Tabel 3.6 Perhitungan Data Chiper Mod q

\begin{tabular}{|c|c|c|c|}
\hline Cipher $(\mathbf{C})$ & M & \multicolumn{2}{|c|}{ K= (c $*$ M) mod q } \\
\hline 962 & 442 & $962 * 442 \bmod 881$ & $\mathbf{5 6 2}$ \\
\hline 1496 & 442 & $1496 * 442 \bmod 881$ & $\mathbf{4 8 2}$ \\
\hline 1263 & 442 & $1263 * 442 \bmod 881$ & $\mathbf{9 2}$ \\
\hline 1129 & 442 & $1129 * 442 \bmod 881$ & $\mathbf{5 7 3}$ \\
\hline 1394 & 442 & $1394 * 442 \bmod 881$ & $\mathbf{3 2 9}$ \\
\hline 1260 & 442 & $1260 * 442 \bmod 881$ & $\mathbf{1 2 8}$ \\
\hline 1157 & 442 & $1157 * 442 \bmod 881$ & $\mathbf{4 1 4}$ \\
\hline
\end{tabular}

3.3.3 Pengurangan Data Dengan Nilai w

$P 1=562-354=208(\mathbf{1})|208-180=28(\mathbf{1})| 28-89=28(\mathbf{0})|28-42=28(\mathbf{0})| 28-21=7(\mathbf{1}) \mid 7-11=$

$7(\mathbf{0})|7-7=0(\mathbf{1})| 0-2=0(\mathbf{0})$

Maka diperoleh hasil $\mathbf{0 1 0 1 0 0 1 1}=\mathrm{S}$

$P 2=482-354=128(\mathbf{1})|128-180=128(\mathbf{0})| 128-89=39(\mathbf{1})|39-42=39(\mathbf{0})| 39-21=18(\mathbf{1}) \mid 18-11=$ 7(1) $|7-7=0(\mathbf{1})| 0-2=0(\mathbf{0})$

Maka diperoleh hasil $01110101=\mathbf{u}$

$$
P 3=573-354=219(\mathbf{1})|219-180=39(\mathbf{1})| 39-89=39(\mathbf{0})|39-42=39(\mathbf{0})| 39-21=18(\mathbf{1}) \mid 18-11=
$$

7(1) $|7-7=0(\mathbf{1})| 0-2=0(\mathbf{0})$

Maka diperoleh hasil $\mathbf{0 1 1 1 0 0 1 1}=\mathbf{s}$

$P 4=372-354=18(\mathbf{1})|18-180=18(\mathbf{0})| 18-89=18(\mathbf{0})|18-42=28(\mathbf{0})| 18-21=18(\mathbf{0}) \mid 18-11=7(\mathbf{1})$

| 7-7 = 0(1) $\mid 0-2=0(\mathbf{0})$

Maka diperoleh hasil $\mathbf{0 1 1 0 0 0 0 1}=\mathbf{a}$

$P 5=329-354=329(0)|329-180=149(1)| 149-89=60(1)|60-42=18(1)| 18-21=18(0) \mid 18-11$

$=7(\mathbf{1})|7-7=0(\mathbf{1})| 0-2=0(\mathbf{0})$ 
Maka diperoleh hasil $01101110=\mathbf{n}$

$$
P 6=128-354=128(0)|128-180=128(0)| 128-89=39(\mathbf{1})|39-42=28(\mathbf{0})| 39-21=18(\mathbf{1}) \mid 18-11
$$

$=7(\mathbf{1})|7-7=0(\mathbf{1})| 0-2=0(\mathbf{0})$

Maka diperoleh hasil $\mathbf{0 1 1 1 0 1 0 0}=\mathbf{t}$ $P 7=414-354=60(1)|60-180=60(0)| 60-89=60(0)|60-42=18(1)| 18-21=18(0) \mid 18-11=7(1)$ | 7-7 = 0(1) $\mid 0-2=0(\mathbf{0})$

Maka diperoleh hasil $01101001=\mathbf{i}$

\section{IMPLEMENTASI DAN UJI COBA}

\subsection{Form Login}

Form Login berfungsi untuk menghubungkan user ke Menu Utama. User diharuskan memasukkan nama user beserta password dengan benar. Jika salah maka Menu Utama tidak akan ditampilkan. Berikut ini tampilan form menu login:

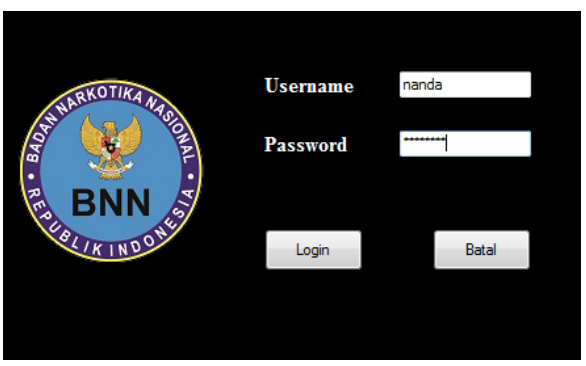

\subsection{Form Menu Utama}

Form menu utama adalah tampilan navigasi. Di mana di dalamnya terdapat menu-menu untuk membuka form lainnya. Form menu utama akan muncul jika sudah berhasil login.

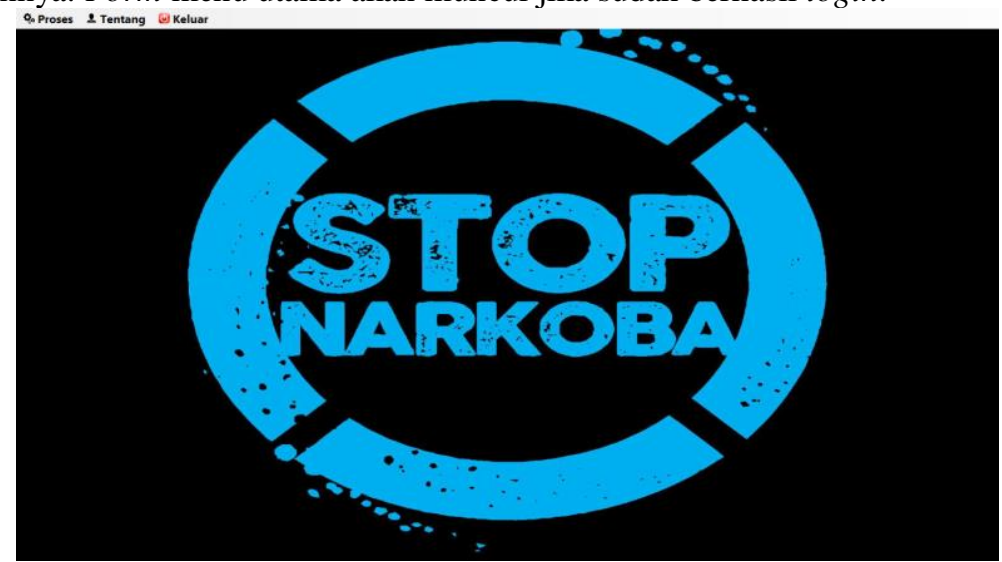

\subsection{Form Enkripsi}

Form Enkripsi digunakan untuk melakukan input data client yang akan dilakukan proses pengamanan. 


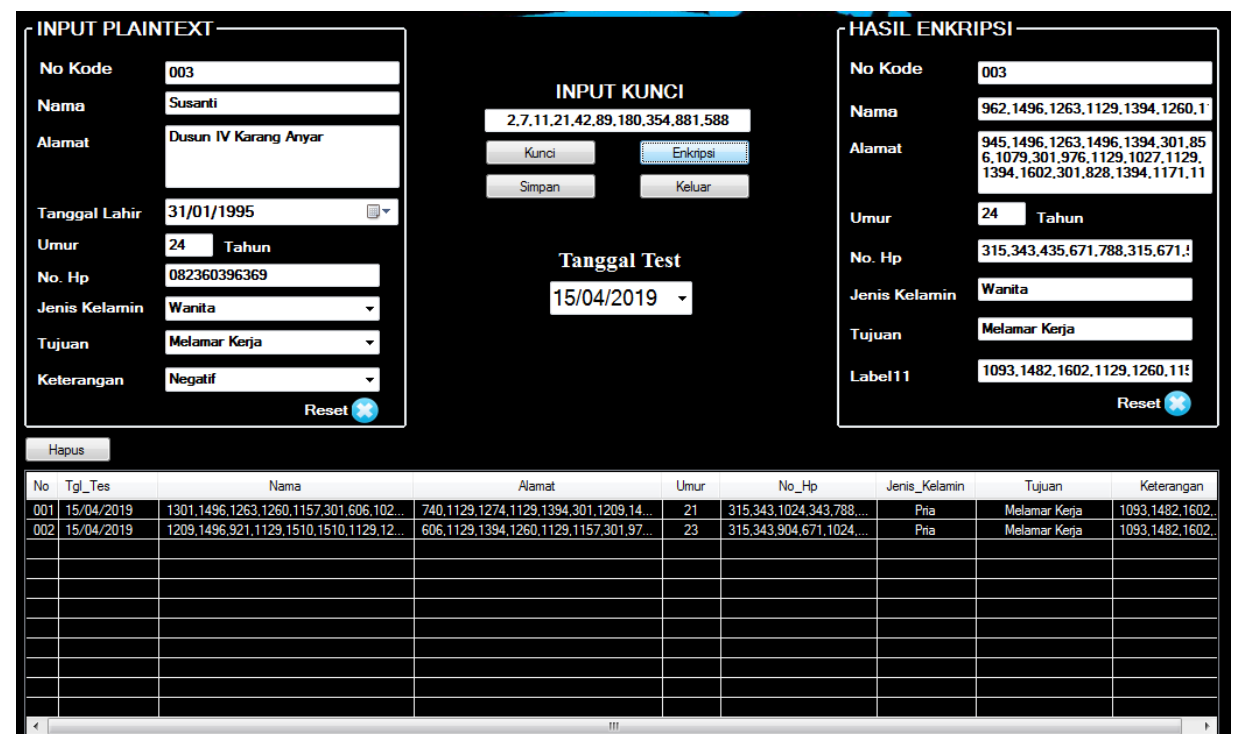

\subsection{Form Dekripsi}

Form dekripsi digunakan untuk mengembalikan data yang telah dienkripsi sebelumnya dan dapat dicetak menjadi sebuah lembar laporan.

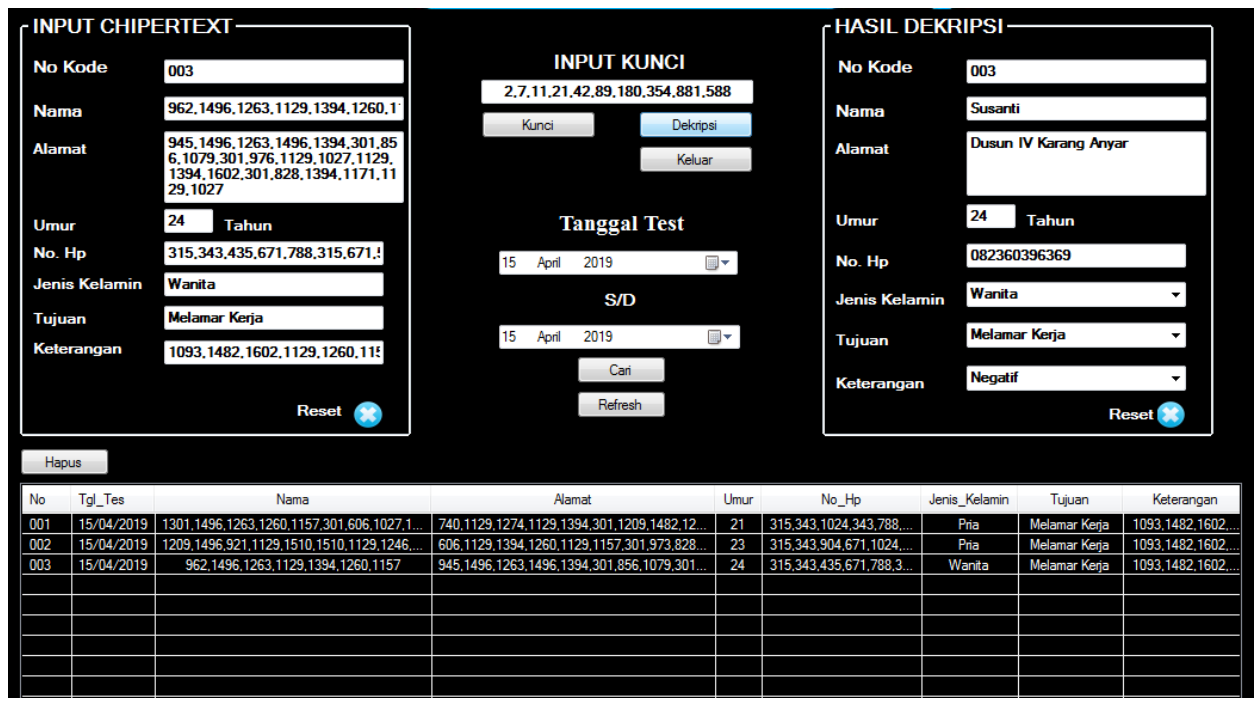

\section{KESIMPULAN}

Dari hasil pembahasan pada bab sebelumnya dan pengamatan yang telah dilakukan maka dapat diambil kesimpulan diantaranya sebagai berikut:

1. Dengan menerapkan metode Merkle Hellman ini mampu untuk memberikan pengamanan terhadap data client test urine, sehingga data tersebut memiliki tingkat keamanan yang tinggi.

2. Mengimplementasikan aplikasi pengamanan data client test urine dilakukan pemprograman dengan menerapkan Metode Merkle Hellman. Dilakukan menggunakan bahasa pemprograman Visual Basic 2008. Dengan terlebih dahulu masuk login menu utama, kemudian masuk ke form Proses Enkripsi lalu input data client, kemudian proses dengan enkripsi dilanjutkan dengan menyimpan ke dalam database. Selanjutnya untuk proses dekripsi, masuk ke form proses dekripsi dengan memilih no kode client yang telah tersimpan lalu data diproses menggunakan perhitungan metode merkle hellman.

3. Pembangunan aplikasi pengamanan dapat dilakukan dengan pengkodean menggunakan bahasa pemrograman berbasis Dekstop Programming.

4. Aplikasi yang dirancang dapat menjadi solusi pemecahan masalah dalam hal pengamanan data client test urine pada BNN Kabupaten Deli Serdang

\section{DAFTAR PUSTAKA}


Ariyus, Dony. 2006. Computer Security. Yogyakarta:C.V Andi Offset

Ariyus, Dony. 2006 Kriptografi Keamanan Data dan Komunikasi, Yogyakarta : Graha Ilmu

Ariyus, Dony. 2009. Keamanan Multimedia. Yogyakarta: C.V Andi Offset

Asriyanik. (2017). Studi Terhadap Advanced Encryption Standard ( Aes ) Dan Algoritma Knapsack Dalam Pengamanan Data. Sains Dan Teknologi, 7(1), 554-561.

Fadlan, M., \& Hadriansa, H. (2017). Rekayasa Aplikasi Kriptografi Dengan Penerapan Kombinasi Algoritma Knapsack Merkle Hellman Dan Affine Cipher. Jurnal Teknologi Informasi Dan Ilmu Komputer, 4(4), 286-274. https://doi.org/10.25126/jtiik.201744468

Hendrayudi. 2011. Dasar-Dasar Pemrograman Microsoft Visual Basic 2008. Bandung: CV Yrama Widya.

Kharisma, R. S., \& Rachman, M. A. F. (2017). Pembuatan Aplikasi Notes Menggunakan Algoritma Kriptografi Polyalphabetic Subtitution Cipher Kombinasi Kode Asii Dan Operasi Xor Berbasis Android. Jurnal Teknologi Informasi, 35, 1-7. https://doi.org/10.1016/j.clnu.2014.08.012

Komputer, Wahana. 2010. The Best Encryption Tools. Jakarta: PT Elex Media Komputindo

Mardalius. (2018). Implementasi Aplikasi Enkripsi dan Dekripsi Text Pada Visual Basic. Net Menggunakan Algoritma Merkle Hellman Knapsack, 9986(September), 249-252.

Murdani. (2017). Perancangan Aplikasi Keamanan Data Teks Menggunakan Algoritma Merkle Hellman Knapsack. Pelita Informatika, 16(3), 302-305.

Rosa, A S., \& Shalahuddin, M. 2013. Rekayasa Perangkat Lunak Terstruktur dan Berorientasi Objek. Bandung: Informatika Bandung.

Siregar, M. (2013). Analisa Dan Perancangan Aplikasi Pengamanan Data Teks Menggunakan Algoritma Merkle Hellman, V(3), 122-126.

Sulianta, Feri. 2017 Teknik Perancangan Arsitektur Sistem Informasi, Yogyakarta: Penerbit Andi

Sulindawati, \& Fathoni, M. (2011). Pengantar Analisa Perancangan “ Sistem “. Jurnal Saintikom, 9(2), 1-19. https://doi.org/10.1097/AOG.0b013e3181660c1b

Ukar, K., \& Pratama, B., G. 2010. Seri Penuntun Praktis Microsoft Access 2010. Jakarta: PT Elex Media Komputindo

Yasin, Verdi. 2012, Rekayasa Perangkat Lunak Berorientasi Obyek. Penerbit

Mitra Wacana Media. 